\title{
Türkiye Kanatlı Eti Sektörünün Uluslararası Rekabetçiliğinin Seçilmiş Ülkelerle Karşılaş̧tırılmalı Analizi
}

\author{
Mustafa TERIN ${ }^{\mathscr{P}}$ (D), Fahri YAVUZ2 ${ }^{2}$ iD \\ ${ }^{1}$ Van Yüzüncü Yıl Üniversitesi, Ziraat Fakültesi, Tarım Ekonomisi Bölümü, 65080 Van, ${ }^{2}$ Atatürk Üniversitesi, Ziraat Fakültesi, Tarım \\ Ekonomisi Bölümü, 25240 Erzurum \\ ${ }^{1}$ https://orcid.org/0000-0002-6550-335X, ${ }^{2}$ https://orcid.org/0000-0002-3413-7748 \\ $\square:$ mustafaterin@yyu.edu.tr
}

\section{ÖZET}

$\mathrm{Bu}$ araştırmanın amacı, Türkiye'nin uluslararası kanatlı eti ticaretindeki rekabet gücünü belirlemek ve dünya kanatlı eti ihracatında öne çıkan Brezilya, ABD, Hollanda, Polonya, Almanya, Fransa, Cin, Tayland ve Ukrayna gibi ülkelerle karşılaştırmaktır. Araştırmanın verileri Uluslararası Ticaret Merkezi veri tabanından (2001-2017) elde edilmiştir. Ülkelerin rekabet güçleri, İhracat Piyasa Payı Endeksi (IPPE), Açıklanmış Karşılaştırmalı Üstünlükler Endeksi (AKÜE) ve Ticaret Dengesi Endeksi (TDE) kullanılarak hesaplanmıştır. Araştırmada, Türkiye'nin IPPE ve AKÜE indeks skorlarının özellikle son yıllarda giderek arttığı ve 2017 yılı itibariyle sırası ile 2.04 ve 2.28'e yükseldiği belirlenmiştir. AKÜE 2017 yılı skorlarına göre, Brezilya, Polonya ve Ukrayna'nın kanatl eti ticaretinde güçlü bir karşılaştırmalı üstünlüğe, Hollanda ve Türkiye'nin orta derece karşlaştırmalı üstünlüğe, ABD, Fransa ve Tayland'ın zayıf karşılaştırmalı üstünlüğe sahip olduğu, Almanya ve Çin’in ise karşılaştırmalı üstünlüğe sahip olmadığı belirlenmiştir. Türkiye'nin var olan ve giderek artan rekabet gücünün devam edebilmesi için üretimde en önemli maliyet unsuru olan yem hammaddesinde dışa bağımlılı̆ğ azaltacak politikaların ve uluslararası yeni pazar alanlarının oluşturulması oldukça önemlidir.

\section{Araştırma Makalesi}

Makale Tarihçesi
Geliş Tarihi $: 12.04 .2019$

Kabul Tarihi : 20.05.2019

Anahtar Kelimeler

Türkiye

Kanatlı eti

Uluslararası ticaret

Rekabet gücü

\section{A Comparative Analysis on International Competitiveness of Turkey's Poultry Meat Sector Among Selected Countries}

\section{ABSTRACT}

The aim of this study was to determine the Turkey's international competitiveness power in poultry meat market and to make a comparison with major players of markets, namely, Brazil, USA, Netherland, Poland, Germany, France Thailand, China and Ukraine. The data were obtained from databases of International Trade Center (2001-2017 years). The competitiveness power of the countries were calculated using the Export Market Share Index (ESI), Revealed Comparative Advantages Index (RCA) and Trade Balance Index (TBI). In the study, Turkey's ESI and RCA index scores especially increased steadily in recent years and as of 2017, ESI and RCA index scores increased to 2.04 and 2.28 respectively. According to the 2017 RCA index score; Brazil, Poland and Ukraine had a strong comparative advantages, Netherland and Turkey had medium comparative advantages, USA, France and Thailand had a weak comparative advantage while Germany and China had no comparative advantages in poultry meat trade. To sustain Turkey's competitiveness, it is very important to reduce foreign dependency in feed raw material which is the most important cost element in production and to create new international market areas.

\section{Research Article}

$\begin{array}{ll}\text { Article History } & \\ \text { Received } & : 12.04 .2019 \\ \text { Accepted } & : 20.05 .2019\end{array}$

Keywords
Turkey
Poultry meat
International trade
Competing power

To Cite : Terin M, Yavuz F 2019. Türkiye Kanatlı Eti Sektörünün Uluslararası Rekabetçiliğinin Seçilmiş Ülkelerle Karşılaştırılmalı Analizi. KSÜ Tarım ve Doğa Derg 22(Ek Sayı 1): 188-194. DOIः 10.18016/ksutarimdoga.vi.553108. 


\section{GİRIŞ}

Dengeli ve sağlıklı beslenme, özellikle son yıllarda önemli oranda teşvik edilmekte ve bunun sonucunda farklı sağlıklı gıda tüketim eğilimleri ortaya çıkmaktadır (Gilbert, 2000; Leek ve ark., 2000). Kanatlı eti, az yağlı ve yüksek protein içeriği, taşıdığı vitamin ve mineral maddeler ve diyetetik özellikteki düşük enerjisi nedeniyle sağlıklı ve dengeli beslenmede oldukça önemli hayvansal kaynaklı bir gıda maddesidir. Bu nedenle Akdeniz diyeti ve yüksek tansiyonu durdurmaya yönelik diyet yaklaşımlarında sıklıkla önerilen bir üründür (Donma ve Donma, 2017).

Dünyada kanatlı eti tüketimi giderek artmakta ve bu artışın gelecek yıllarda bölge ve gelir seviyesine bakılmaksızın artmaya devam edeceği ve dünya genelinde 2016-2025 döneminde kişi başına düşen toplam et tüketiminin hemen hemen yarısının kanatlı eti tüketimi tarafindan karşılanacağı öngörülmektedir (OECD/FAO, 2018). Dünyada kişi başına düşen kanatlı eti tüketim miktarı 2000 yılında $9.7 \mathrm{~kg}$ iken, 2017 yılında $13.9 \mathrm{~kg}$ yükselmiştir. Dünyada kanatlı eti tüketimin en yüksek olduğu ülkeler İsrail $(58.6 \mathrm{~kg})$, ABD (48.9 kg), Malezya (46.5 kg) ve Avusturalya (44.0 kg) iken, en düşük olduğu ülkeler Etiyopya (0.5 kg), Nijerya $(1.3 \mathrm{~kg})$, Hindistan $(2.1 \mathrm{~kg})$ ve Pakistan $(4.5$ kg)'dır. AB'de kişi başına kanatlı tüketimi 24.2 kg'dır (OECD, 2018). Türkiye'de kişi başına düşen kanatlı eti tüketim miktarı 2000 yılında $10.9 \mathrm{~kg}$ iken, 2016 yılı itibariyle $23.2 \mathrm{~kg}$ yükselmiştir (BESD-BİR, 2018).

Artan dünya nüfusu ile birlikte gelişmekte olan ülkelerde meydana gelen ekonomik gelişmeler ve kentleşme insanların hayvansal kaynaklı gıdaya olan taleplerini arttırmaktadır. Bu durum kanatlı eti üretiminin artmasına neden olmaktadır. Dünya kanatlı eti üretimi 2000 yllında 69 milyon ton iken, 2017 yllında 120 milyon tona yükselmiş ve dünya toplam et üretimindeki payı \%36.4'e yükselmiştir (FAO, 2018). Dünya kanatlı eti üretiminin 2026 yılında 132 milyon tona ulaşması öngörülmektedir (OECD/FAO, 2017). Dünya, 2017 yılı itibariyle kanatı eti üretiminde ilk sırayı 22 milyon ton ile ABD alırken, bunu sırası ile Çin (17.5 milyon ton), AB (14.6 milyon ton), Brezilya (13.6 milyon ton), Rusya (4.5 milyon ton), Hindistan (3.6 milyon ton) ve Meksika (3.2 milyon ton) izlemektedir. Türkiye 2.18 milyon ton üretim ile dünya sıralamasında 9. sırada yer almaktadır (FAO, 2018).

Kanatlı eti beslenmedeki öneminin yanı sıra uluslararası ticarette de önemli bir yere sahiptir. Dünya 2017 yılı toplam et ticaretinin (32.8 milyon ton), \%40.0'ını (13.1 milyon ton) kanatlı eti ticareti oluşturmaktadır. Dünya kanatlı eti ticareti 2005 yılında 8.4 milyon ton iken, 2010 yılında 11.7 milyon ton'a ve 2017 yılında 13.1 milyon ton'a yükselmiştir (FAO, 2018). Dünya kanatlı eti ihracatında Brezilya uzun yıllardan beri ilk sırada yer almaktadır. Brezilya'nın 2001 yılındaki kanatlı eti ihracatı 1.4 milyar dolar iken, 2017 yılında 6.6 milyar dolara yükselmiştir. Kanatlı eti ihracatında öne çıkan diğer ülkeler sirasiyla ABD (3.6 milyar \$), Hollanda (2.1 milyar \$), Polonya (1.1 milyar \$), Hong Kong (1 milyar $\$$ ) ve Almanya (993 milyon \$) dır. Türkiye, 2017 yılı itibariyle 527 milyon $\$$ kanatlı eti ihracatı ile dünya siralamasında 12. sirada yer almaktadır (INTRACEN, 2018).

Literatürde, ürün veya sektör bazında rekabet gücünün ölçülmesine yönelik olarak yapılmış yerli ve yabancı birçok çalışma bulunmaktadır. Ancak bu çalışmaların önemli bir kısmının imalat sanayi sektörüne ait olduğu söylenebilir. Son yıllarda özellikle dünya gıda fiyatlarında meydana gelen artışlar, güvenli gıdaya erişimin öneminin giderek artması ve dünya tarım ürünleri ticaretinde yaşanan bir takım sorunlar, tarım sektöründe rekabet gücü ölçüm çalışmalarının yapılmasına neden olmuştur. Tarım sektörü ve kanatlı eti alt sektörü ile ilgili yapılan rekabet gücü analiz çalışmaları aşağıdaki gibi sarılanabilir;

Çoban ve ark (2010), tarafından yapılan çalışmada Türk tarım sektörünün $\mathrm{AB}$ ülkeleri karşısındaki rekabet gücü RCA endeksi kullanılarak ölçülmüş ve Türkiye'nin meyve-sebze, şeker-bal ve şeker hammaddesi ürün gruplarında yüksek rekabet gücüne, canlı hayvan ürün grubunda ise oldukça düşük rekabet gücüne sahip olduğu tespit edilmiştir. Erkan ve ark (2015), tarafından yapılan çalışmada Türkiye'nin sebze ihracatındaki rekabet gücü ölçülmüş ve Türkiye'nin, sebze ve alt grupları ihracatında önemli bir karşılaştırmalı üstünlüğe sahip olduğu ancak, son yıllarda bu üstünlüğün nispi anlamda giderek azaldığı belirlenmiştir. Şahinli (2012), Türkiye'nin AB ülkeleri ile canlı hayvan rekabet gücünü RCA endeksi ile karşılaştırmıştır. Çalışmada, Türkiye'nin AB üyesi ülkelere göre canlı hayvan ticaretinde rekabet gücüne sahip olmadığ tespit edilmiştir. Saraçoğlu (2015), Türkiye'nin geleneksel ihraç ürünleri olan findık, kuru üzüm, kuru kayısı ve kuru incirin AB ile olan rekabet gücünü 19952011 dönemi için analiz etmiştir. Çalışmada, Türkiye'nin her bir üründe AB ülkelerine göre rekabet gücüne sahip olduğu belirlenmiştir. Terin ve ark (2018), Türkiye'nin Balkan ülkeleri ile bal rekabet gücünü RCA ve TBI endeksi ile analiz etmişlerdir. Çalışmada Türkiye'nin bal ticaretinde zayıf bir karşlaştırmalı üstünlüğe sahip olduğu ve bal ticaretinde net ihracatçı olduğu belirlenmiştir. Bojnec ve Ferto (2014), AB'ye üye 27 ülkenin süt ve süt ürünleri ihracatının rekabet gücünü RCA indeksini kullanarak 2000-2011 dönemi için ölçmüşlerdir. Çalışma sonuçlarına göre, Belçika, Danimarka, Fransa, İrlanda ve Hollanda gibi ülkelerin süt ürünleri ihracatında rekabetçi oldukları, bununla birlikte 
birliğe daha sonra katılan Estontya, Latviya, Litvanya ve Polonya gibi ülkelerin de süt ürünleri ihracatında daha fazla rekabetçi oldukları tespit edilmiştir. Kandanuri (2014), Hindistan'ın et ihracatın, dünya et ihracatında önemli paya sahip Avusturalya, Fransa, Almanya, İrlanda, ABD gibi bazı ülkeler karşısındaki rekabet gücünü 2006-2011 yılları için RSCA indeksini kullanarak analiz etmiştir. Çalışmada, Hindistan dondurulmuş sığır eti ihracatında rakip ülkeler karşısında büyük ölçüde rekabet gücüne sahip olduğu, ancak gelecekte rakip ülkelerden ABD'nin et ihracatında Hindistan için önemli bir rakip ülke olacağı vurgulanmıştır. Sahinli ve Abdul-Kareem (2018), tarafından yapılan çalışmada Türkiye ile Brezilya'nın tavuk eti sektöründeki rekabet gücü 2010-2014 dönemi için RCA endeksi kullanılarak analiz edilmiştir. Çalışmada, Brezilya'nın Türkiye'ye göre tavuk eti ticaretinde daha fazla rekabet gücüne sahip olduğu, ancak Türkiye'nin incelenen dönemde RCA endeks sonuçlarının sürekli olarak arttığına vurgu yapılmıştır. Horne (2018), çalışmasında AB'ye üye ve üye olmayan seçilmiş ülkelerin kanatlı eti sektöründeki rekabet gücünü farklı senaryoları (düşük ithalat vergisi ve farklı döviz kurları) dikkate alarak belirlemeye çalışmıştır. Kanatlı eti sektöründeki ithalat vergisinin \%50 düşürülmesi senaryosuna göre; Brezilya, Ukrayna ve Tayland'ın AB'ye göre daha rekabetçi olduğu, ABD, Rusya ve Arjantin'in ise AB'ye göre daha az rekabetçi olduğu belirlenmiştir. Saran ve ark (2013) tarafından yapılan çalışmada Hindistan'ın kanatlı eti ve ürünlerindeki ihracat potansiyeli ve rekabet gücünü RCA endeksi ile analiz etmişlerdir. Calışmada Hindistan'ın tavuk eti, ördek eti ve hindi etinde rekabet gücünün olmadiğ yumurtasında (kabuklu ve sıvı) rekabet gücüne sahip olduğu belirlenmiştir.

Rekabet gücü veya avantajı, bir ülkenin üretim becerilerinin ve kapasite artışının organizasyonu olarak kabul edilmektedir. (Sahinli ve Abdul-Kareem, 2018). Küreselleşme sürecinin tüm dünyayı etkisi altına aldığı günümüzde uluslararası ticarette rekabet gücüne sahip olmak ülke ekonomilerinin büyüme ve gelişmesini tetikleyen en önemli faktörlerden biridir. Uluslararası ticarette rekabet gücünün ölçülmesindeki temel amaçlarından biri firmaların, sektörlerin ve ülkelerin ekonomilerinin performansinı belirlemektir. Bir ülkenin küresel düzeydeki rekabet gücü, ülke içindeki sektörlerin sahip olduğu rekabet güçlerinden oluşmaktadır. $\mathrm{Bu}$ nedenle, sektörel rekabet güçlerinin belirlenmesi oldukça önemlidir.

Türkiye'de kanatlı eti sektörü yıllar içinde çok hızlı bir gelişme göstermiş ve gerek üretim, gerekse ihracat miktarları hızla artmıştır. Türkiye'de hayvancılık sektörü içinde kanatlı eti sektörünün başta $\mathrm{AB}$ ülkeleri olmak üzere birçok ülke ile rekabete edebilecek seviyede olduğu ifade edilmektedir (Terin ve ark., 2010; Keskin ve Demirbaş, 2012; Aydoğdu,
2018). Bu nedenle sektörün uluslararası ticaretteki rekabet gücünün hesaplanması ve uluslararası kanatlı eti ticaretinde öne çıkan ülkelerle karşılaştırılması önemli görülmüştür. Bu doğrultudan hareketle çalışmanın amacı, Türkiye'nin uluslararası kanatlı eti ticaretindeki rekabet gücünü belirlemek ve dünya kanatlı eti ihracatında öne çıan Brezilya, ABD, Hollanda, Polonya, Almanya, Fransa, Çin, Tayland ve Ukrayna ile karşılaş̧ırmaktır.

\section{MATERYAL ve YÖNTEM}

Çalışmanın ana materyalini Uluslararası Ticaret Merkezi (INTRACEN) veri tabanından elde edilen ticaret verileri oluşturmaktadır. Araştırmada Armonize Mal Tanım ve Kodlama Sistemi (HS Code) kullanılmıştır. HS sisteminde kümes hayvanları eti ve yenilebilir sakatatları ürününün fasıl numarası 0207'dir. Araştırmada 2001-2017 veri seti kullanılmıştır. Bunun yanı sıra konu ile ilgili yayınlanmış yerli, yabancı makale, rapor ve istatistiklerden faydalanılmıştır. Literatürde, rekabet gücünü ölçen çok sayıda yöntem bulunmaktadır. Çalışmada rekabet gücünü hesaplama yöntemi olarak İhracat Piyasa Payı Endeksi (IPPPE), Açıklanmış Karşılaştırmalı Üstünlükler Endeksi (AKÜE) ve Ticaret Dengesi Endeksi (TDE) kullanılmıştır. Söz konusu indeksler basit hesaplanabilmesi nedeniyle ampirik çalışmalarda yaygın olarak kullanılmaktadır. IPP indeksi, belli bir sektörde uluslararası piyasada ülkenin rekabet gücünü ölçmektedir. İhracat piyasa payı indeksi aşağıdaki şekilde formüle edilmektedir:

$$
\dot{\mathrm{I}} P P=\left(\frac{X_{i k}}{X_{w k}}\right) * 100
$$

Formülde, $\mathrm{X}_{\text {ik }}$ 'i’ ülkesinin ' $\mathrm{k}$ ' sektörünün ihracatını ve $\mathrm{X}_{\mathrm{wk}}$ ' $\mathrm{k}$ ' sektörü dünya ihracatını ifade etmektedir. İhracat Piyasa Payı Endeksi, 0 ile 100 arasında bir değer almaktadır. (Kijboonchoo ve Kalayanakupt, 2003; Erkan, 2009; Bashimov, 2017; Terin ve Yavuz, 2018).

AKÜ endeksi ilk kez Liesner (1958) tarafindan ortaya atılmış, daha sonra ise Balassa (1965) tarafindan yeniden tanımlanarak geliştirilmiştir. AKÜ endeksi, uluslararası ticarette uzmanlaşmayı ölçmeye yarayan bir indeks olup literatürde yaygın olarak kabul görmektedir (Kanaka ve Chinadurai, 2012; Pilinkiene, 2014; Torok ve Jambor, 2016; Terin ve ark., 2018; Güvenç, 2019). AKÜ endeksi bir ülkenin güçlü ve zayıf ihracatçı sektörlerini belirlemeye yönelik çalışmalarda kullanılmaktadır (Aiginger, 2000; Bojnec ve Fertö, 2007). Buradaki amaç, karşılaştırmalı üstünlüğün altında yatan kaynakları belirlemekten çok, ülkenin karşılaştırmalı üstünlüğe sahip olup-olmadığının belirlenebilmesidir (Çakmak, 2005; Utkulu ve İmer, 2009). AKÜ indeksi şu şekilde formüle edilmektedir (Balassa, 1965). 


$$
A K \ddot{\mathrm{U}}_{i j}=\left[\left(\frac{X_{i j}}{X_{i}}\right) /\left(\frac{X_{w j}}{X_{w}}\right)\right]
$$

Burada, AKÜ $\ddot{\mathrm{ij}}_{\mathrm{j}}$, ‘i’ ülkesinin ‘j’ sektörü için açıklanmış karşılaştırmalı üstünlükler endeksini, $\mathrm{X}_{\mathrm{ij}}$ 'i’ ülkesinin ‘j’ sektörünün ihracatını, $X_{i}$ ' $i$ ' ülkesinin toplam ihracatını, $X_{w j}$ ' $j$ ' sektörü dünya ihracatını ve $X_{w}$ toplam dünya ihracatını göstermektedir. AKÜ endeksi 0 ile $\infty$ arasında bir değer almaktadır. Ĕğer endeks değeri birden büyükse o ülkenin ilgili sektörde karşılaştırmalı üstünlüğe sahip olduğu ve uzmanlaştığı söylenir (Coxhead, 2007). Eğer endeks değeri birden küçük ise ülkenin ilgili sektörde karşılaştırmalı dezavantaja sahip olduğu söylenir (Vlachos, 2001; Havrila ve Gunawardana, 2003; Dukic ve ark., 2017).

Çalışmada, rekabet gücünün ölçülmesinde kullanılan son endeks, Ticaret Dengesi Endeksi (TDE) dir. TDE, bir ülkenin belirli bir malda net ihracatçı veya net ithalatçı ülke olup olmadığını belirlemek için kullanılmakta ve aşağıdaki şekilde formüle edilmektedir (Lafay, 1992; Widodo, 2008).

$T D \dot{\mathrm{I}}_{i j}=\frac{X_{i j}-M_{i j}}{X_{i j}+M_{i j}}$

$\mathrm{Bu}$ formülde, $\mathrm{TDI}_{\mathrm{ij}} \mathrm{i}$ ülkesinin $\mathrm{j}$ malı ticaret dengesi endeksini göstermektedir. $\mathrm{X}_{\mathrm{ij}}$ ve $\mathrm{M}_{\mathrm{ij}}$ ise $\mathrm{i}$ ülkesinin $\mathrm{j}$ malı ihracatını ve ithalatını göstermektedir. $\mathrm{Bu}$ endeks -1 ile +1 arasında bir değer almaktadır. Eğer TDI $\dot{\mathrm{I}}_{\mathrm{ij}}>0$ ise ülke söz konusu malda net ihracatçı, Eğer $\mathrm{TDI}_{\mathrm{ij}}<0$ ise ülke söz konusu malda net ithalatçı konumdadır (Ullah ve Kazuo, 2013; Altay Topçu ve Sümerli Sarıgül, 2015; Terin ve Yavuz, 2018).

\section{BULGULAR ve TARTIŞMA}

Türkiye ve dünya kanatlı eti ihracatında öne çıkan ülkelerin İhracat Piyasası endeks sonuçları Çizelge 1 'de verilmiştir.

Çizelge 1. İhracat Piyasası Endeks sonuçları

\begin{tabular}{lllllllllll} 
Ylllar & TR & BR & ABD & Hollanda & Polonya & Almanya & Fransa & Cin & Tayland & Ukrayna \\
\hline 2001 & 0.15 & 14.49 & 21.36 & 11.33 & 1.08 & 2.69 & 11.61 & 6.20 & 5.98 & 0.00 \\
2002 & 0.13 & 16.26 & 17.46 & 12.03 & 1.42 & 3.87 & 11.49 & 4.53 & 6.52 & 0.04 \\
2003 & 0.16 & 18.38 & 17.23 & 10.37 & 2.37 & 4.64 & 11.16 & 3.15 & 6.29 & 0.01 \\
2004 & 0.18 & 24.69 & 18.60 & 10.37 & 2.73 & 4.49 & 10.69 & 1.32 & 0.43 & 0.00 \\
2005 & 0.26 & 26.94 & 19.18 & 9.94 & 3.61 & 4.72 & 8.80 & 1.50 & 0.12 & 0.00 \\
2006 & 0.22 & 25.07 & 18.46 & 11.53 & 4.37 & 5.29 & 7.95 & 1.38 & 0.17 & 0.00 \\
2007 & 0.26 & 25.83 & 19.31 & 11.47 & 4.73 & 4.45 & 7.17 & 1.55 & 0.24 & 0.04 \\
2008 & 0.41 & 28.83 & 19.93 & 9.68 & 4.53 & 4.13 & 6.71 & 1.55 & 0.25 & 0.05 \\
2009 & 0.80 & 26.11 & 20.34 & 9.42 & 4.28 & 4.64 & 6.25 & 1.77 & 0.30 & 0.10 \\
2010 & 0.94 & 27.57 & 17.68 & 9.21 & 4.43 & 4.40 & 5.64 & 1.98 & 0.32 & 0.19 \\
2011 & 1.46 & 27.48 & 17.09 & 10.51 & 4.74 & 4.25 & 5.62 & 1.99 & 0.44 & 0.30 \\
2012 & 1.98 & 26.05 & 18.83 & 10.48 & 4.84 & 4.42 & 5.10 & 1.88 & 0.74 & 0.54 \\
2013 & 2.21 & 26.16 & 18.11 & 8.85 & 5.35 & 4.60 & 5.19 & 1.87 & 0.79 & 0.84 \\
2014 & 2.30 & 24.85 & 17.40 & 9.36 & 6.33 & 4.64 & 4.59 & 2.03 & 1.46 & 0.97 \\
2015 & 1.80 & 26.31 & 14.31 & 9.56 & 7.41 & 4.42 & 4.70 & 2.51 & 1.78 & 0.93 \\
2016 & 1.52 & 25.78 & 13.95 & 9.74 & 7.78 & 4.21 & 3.98 & 2.25 & 2.15 & 1.23 \\
2017 & 2.04 & 25.43 & 14.02 & 9.97 & 8.15 & 3.94 & 3.72 & 2.16 & 2.36 & 1.51 \\
\hline Ort. & $\mathbf{0 . 9 9}$ & $\mathbf{2 4 . 4 8}$ & $\mathbf{1 7 . 8 4}$ & $\mathbf{1 0 . 2 3}$ & $\mathbf{4 . 6 0}$ & $\mathbf{4 . 3 4}$ & $\mathbf{7 . 0 8}$ & $\mathbf{2 . 3 3}$ & $\mathbf{1 . 7 9}$ & $\mathbf{0 . 4 0}$ \\
\hline
\end{tabular}

Kaynak: Orijinal hesaplamalar. TR: Türkiye, BR: Brezilya (INTRACEN, 2018)

$\mathrm{Bu}$ sonuçlara göre Türkiye'nin dünya kanatlı eti ihracatı piyasasındaki payı giderek artmaktadır. Türkiye'nin payı 2001 yılında binde 15'ler civarında iken, 2011 yılında \%1.1'e ve 2017 yllında ise \%2.03 yükselmiştir. Türkiye'nin en önemli kanatlı eti ihracat pazarı Irak'tır. Türkiye, kanatlı eti ihracatının yaklaşık \%62.0'sini Irak'a yapmaktadır (INTRACEN, 2018). Dünya kanatlı eti ihracatı piyasasında Brezilya uzun yıllardan beri ilk sirada yer almaktadır. Brezilya'nın son yıllarda kanatlı eti ihracatı piyasasındaki payı az da olsa düşmesine karşın, halen \%25.43'lük paya sahiptir. En önemli pazarları Sudi Arabistan (\%15.0), Japonya (\%14), Çin (\%12) ve Birleşik Arap Emirlikleri'dir (\%8). ABD'nin kanatlı eti ihracatındaki pay son ylllarda önemli oranda düşmesine karşın, halen önemli bir paya (\%14.02) sahiptir. Çin üretimde önemli bir ülke olmasına karşın, ihracattaki payı giderek azalmakta ve 2017 yılı itibariyle \%2.16'ya gerilemiştir. AB ülkeleri içinde Polonya'nın payı çok hızlı artarken, Fransa'nın payı giderek düşmekte, buna karşılık Hollanda istikrarlı bir şeklide ihracattaki payını \%10'larda tutmaktadır. Son yıllarda Ukrayna dünya kanatlı eti ihracat piyasasında kendine yer bulmuş ve 2001 yılında neredeyse sıfir olan payı 2017 'de \%1.51'e yükselmiştir. Eğilimin böyle devam etmesi halinde Ukrayna, Türkiye için önemli bir rakip olabilecektir. Çünkü Ukrayna toplam kanatlı eti ihracatının yaklaşı \%25'lik kısmını Irak'a gerçekleştirmektedir.

Türkiye ve dünya kanatlı eti ihracatında öne çıkan ülkelerin AKÜ endeks sonuçları Çizelge 2'de verilmiştir. 
Çizelge 2. Açıklanmış Karşılaştırmalı Üstünlük Endeks sonuçları

\begin{tabular}{|c|c|c|c|c|c|c|c|c|c|c|}
\hline Yillar & TR & BR & ABD & Hollanda & Polonya & Almanya & Fransa & Çin & Tayland & Ukrayna \\
\hline 2001 & 0.29 & 15.23 & 1.79 & 3.21 & 1.87 & 0.29 & 2.46 & 1.43 & 5.64 & 0.02 \\
\hline 2002 & 0.24 & 17.29 & 1.62 & 3.52 & 2.27 & 0.40 & 2.42 & 0.89 & 6.15 & 0.14 \\
\hline 2003 & 0.26 & 18.79 & 1.78 & 2.93 & 3.37 & 0.46 & 2.33 & 0.54 & 5.87 & 0.02 \\
\hline 2004 & 0.26 & 23.24 & 2.08 & 2.97 & 3.37 & 0.45 & 2.35 & 0.20 & 0.40 & 0.01 \\
\hline 2005 & 0.37 & 23.50 & 2.20 & 2.94 & 4.18 & 0.50 & 2.09 & 0.20 & 0.12 & 0.00 \\
\hline 2006 & 0.31 & 21.75 & 2.13 & 3.44 & 4.77 & 0.56 & 1.98 & 0.17 & 0.15 & 0.00 \\
\hline 2007 & 0.33 & 22.24 & 2.30 & 3.32 & 4.72 & 0.46 & 1.84 & 0.18 & 0.21 & 0.10 \\
\hline 2008 & 0.50 & 23.27 & 2.45 & 2.83 & 4.21 & 0.45 & 1.80 & 0.17 & 0.23 & 0.13 \\
\hline 2009 & 0.96 & 21.08 & 2.38 & 2.69 & 3.87 & 0.51 & 1.66 & 0.18 & 0.25 & 0.32 \\
\hline 2010 & 1.25 & 20.60 & 2.09 & 2.82 & 4.26 & 0.52 & 1.66 & 0.19 & 0.24 & 0.56 \\
\hline 2011 & 1.96 & 19.40 & 2.09 & 3.58 & 4.56 & 0.52 & 1.74 & 0.19 & 0.35 & 0.79 \\
\hline 2012 & 2.38 & 19.74 & 2.24 & 3.49 & 4.95 & 0.58 & 1.68 & 0.17 & 0.59 & 1.46 \\
\hline 2013 & 2.76 & 20.51 & 2.18 & 2.94 & 4.98 & 0.60 & 1.73 & 0.16 & 0.66 & 2.53 \\
\hline 2014 & 2.76 & 20.95 & 2.04 & 3.11 & 5.60 & 0.59 & 1.54 & 0.16 & 1.22 & 3.43 \\
\hline 2015 & 2.07 & 22.72 & 1.57 & 3.33 & 6.29 & 0.55 & 1.57 & 0.18 & 1.39 & 4.05 \\
\hline 2016 & 1.71 & 22.29 & 1.54 & 3.50 & 6.34 & 0.50 & 1.30 & 0.17 & 1.61 & 5.42 \\
\hline 2017 & 2.28 & 20.53 & 1.59 & 3.47 & 6.47 & 0.48 & 1.25 & 0.17 & 1.76 & 6.10 \\
\hline Ort. & 1.22 & 20.77 & 2.00 & 3.18 & 4.48 & 0.50 & 1.85 & 0.32 & 1.58 & 1.47 \\
\hline
\end{tabular}

Kaynak: Orijinal hesaplamalar. TR: Türkiye, BR: Brezilya (INTRACEN, 2018)

Türkiye uluslararası kanatlı eti ihracatında 2009 yılına kadar karşılaştırmalı üstünlüğe sahip değilken sonraki yıllarda rekabet gücü giderek artmış ve 2017 yılı itibariyle orta derece karşılaştırmalı üstünlüğe ulaşmıştır. Bashimov (2017), Sahinli ve AbdulKareem (2018) ve Altay Topçu (2018) tarafından yapılan çalışmalarda da Türkiye'nin karşılaştırmalı üstünlüğe sahip olduğu tespit edilmiştir. AKÜ endeks sonuçlarına göre dünya kanatlı eti ihracatı piyasasında Brezilya ve Polonya kanatlı eti ticaretinde güçlü bir karşlaştırmalı üstünlüğe, Hollanda ve Türkiye'nin orta derece karşılaştırmalı üstünlüğe,
ABD, Fransa ve Tayland'ın zayıf karşılaştırmalı üstünlüğe sahip olduğu, Almanya ve Çin'in ise karşılaştırmalı üstünlüğe sahip olmadığı belirlenmiştir. Ukrayna 2012 yllına kadar karşılaştırmalı üstünlüğe sahip değilken, sonraki yıllarda rekabet gücü hızla artmış ve 2017 yılı itibariyle güçlü bir karşılaştırmalı üstünlüğe ulaşmıştır.

Türkiye ve dünya kanatlı eti ihracatında öne çıan ülkelerin Ticaret Dengesi Endeks sonuçları Çizelge 3 ’te verilmiştir.

Çizelge 3. Ticaret Dengesi Endeks sonuçları

\begin{tabular}{lllllllllll} 
Ylllar & TR & BR & ABD & Hollanda & Polonya & Almanya & Fransa & Çin & Tayland & Ukrayna \\
\hline 2001 & 0.97 & 1.00 & 0.97 & 0.65 & 0.65 & -0.59 & 0.59 & 0.15 & 1.00 & -0.99 \\
2002 & 0.99 & 1.00 & 0.95 & 0.57 & 0.72 & -0.42 & 0.57 & -0.03 & 1.00 & -0.79 \\
2003 & 0.99 & 1.00 & 0.95 & 0.41 & 0.86 & -0.34 & 0.52 & -0.18 & 1.00 & -0.97 \\
2004 & 1.00 & 1.00 & 0.94 & 0.44 & 0.58 & -0.30 & 0.45 & -0.03 & 0.79 & -1.00 \\
2005 & 0.99 & 1.00 & 0.95 & 0.45 & 0.73 & -0.32 & 0.38 & -0.26 & 0.90 & -1.00 \\
2006 & 1.00 & 1.00 & 0.92 & 0.48 & 0.78 & -0.23 & 0.33 & -0.47 & 0.92 & -1.00 \\
2007 & 1.00 & 1.00 & 0.92 & 0.48 & 0.83 & -0.25 & 0.25 & -0.57 & 0.94 & -0.80 \\
2008 & 0.98 & 1.00 & 0.93 & 0.45 & 0.88 & -0.25 & 0.22 & -0.54 & 0.93 & -0.94 \\
2009 & 0.98 & 1.00 & 0.92 & 0.47 & 0.87 & -0.16 & 0.13 & -0.49 & 0.97 & -0.83 \\
2010 & 0.99 & 1.00 & 0.91 & 0.50 & 0.91 & -0.15 & 0.10 & -0.38 & 0.95 & -0.62 \\
2011 & 0.99 & 1.00 & 0.93 & 0.48 & 0.93 & -0.20 & 0.08 & -0.25 & 0.94 & 0.13 \\
2012 & 1.00 & 1.00 & 0.92 & 0.50 & 0.93 & -0.15 & 0.05 & -0.31 & 0.96 & -0.04 \\
2013 & 1.00 & 1.00 & 0.92 & 0.53 & 0.93 & -0.16 & 0.05 & -0.32 & 0.85 & 0.39 \\
2014 & 1.00 & 1.00 & 0.91 & 0.56 & 0.93 & -0.16 & -0.01 & -0.21 & 0.92 & 0.65 \\
2015 & 0.99 & 1.00 & 0.84 & 0.53 & 0.93 & -0.19 & 0.00 & -0.21 & 0.97 & 0.72 \\
2016 & 1.00 & 1.00 & 0.84 & 0.54 & 0.92 & -0.22 & -0.10 & -0.41 & 0.98 & 0.79 \\
2017 & 0.99 & 1.00 & 0.87 & 0.47 & 0.92 & -0.25 & -0.11 & -0.30 & 1.00 & 0.78 \\
\hline Ort. & $\mathbf{0 . 9 9}$ & $\mathbf{1 . 0 0}$ & $\mathbf{0 . 9 2}$ & $\mathbf{0 . 5 0}$ & $\mathbf{0 . 8 4}$ & -0.25 & $\mathbf{0 . 2 1}$ & -0.28 & $\mathbf{0 . 9 4}$ & -0.32 \\
\hline
\end{tabular}

Kaynak: Orijinal hesaplamalar. TR: Türkiye, BR: Brezilya (INTRACEN, 2018) 
Bu sonuçlara göre Türkiye, Brezilya, ABD, Polonya, Hollanda ve Tayland uluslararası buğday ticaretinde net ihracatçı ülke konumunda iken, Almanya ve Çin uzun yıllardan beri net ithalatçı ülke konumundadır. Fransa 2014 ve 2017 yılları hariç diğer yıllarda net ihracatçı ülke, Ukrayna'da 2013-2017 yılları hariç diğer yıllarda net ithalatçı ülke konumundadır.

\section{SONUÇ ve ÖNERILLR}

Araştırmada, Türkiye'nin uluslararası kanatlı eti ticaretinde, ihracat piyasa payının giderek arttığ derece karşlaş̧tırmalı avantaja sahip olduğu ve uluslararası kanatlı eti ticaretinde net ihracatçı olduğu belirlenmiştir. Türkiye'nin AKÜ endeks sonuçlarının son yıllarda ABD, Almanya, Fransa, Çin ve Tayland'dan daha yüksek olduğu tespit edilmiştir. Türkiye'nin kanatlı eti ihracat piyasasındaki payının giderek artması, aynı zamanda karşılaştırmalı avantajının da artmasına olumlu katkı sağlayacaktır. Bu nedenle Türkiye'nin kanatlı eti ihracatında mevcut pazarlarına yaptığı ihracatı arttırması ve aynı zamanda alternatif yeni pazarlar bulması oldukça önemlidir. Son yıllarda Türk Lirasında yaşanan değer kayıpları dikkate alındığında bu durumun Türkiye'nin kanatlı eti ihracatındaki rekabet gücüne olumlu yansıması düşünülmektedir. Bunun yanı sıra kanatlı eti üretiminde en önemli masraf kalemi olan yem maliyetleri ve yem hammaddesinde dışa bağımlılığın azaltılması yönünde yapılacak politika uygulamaları ve teşvikler ile Türkiye'nin var olan rekabet gücünün daha da artması sağlanabilecektir. Sektörün rekabet gücünün artması, sektörde üretimin ve istihdamin artmasına dolayısıyla ülke ekonomisinin gelişmesi ve büyümesine katkı sağlayacaktır.

\section{KAYNAKLAR}

Aiginger K 2000. Specialization of European manufacturing. Australian Economic Quarterly, 2: 81-92.

Altay Topcu B, Sümerli Sarıül S 2015. Comparative advantage and the product mapping of exporting sectors in Turkey. The Journal of Academic Social Science, 3(18): 330-348.

Altay Topçu B 2018. Türkiye'nin Tarımsal Ürünlerdeki Rekabet Gücü: Gıda Ve Canlı Hayvan Ürünler. International Journal of Social Science, 70: 389-404.

Aydogdu MH 2018. General Analysis of Recent Changes in Poultry Meat Consumptions in Turkey. International Journal of Advances in Agriculture Sciences, 3(12): 06-11.

Balassa B 1965. Trade liberalization and revealed comparative advantage. The Manchester School, 33: 99-123.
Bashimov G 2017. Buğday ihracatında Kazakistan'ın Rekabet Gücü. Uludağ Üniversitesi Ziraat Fakültesi Dergisi, 31(2): 11-21.

Bashimov G 2017. Türkiye'nin Tarımsal Ürünlerdeki Rekabet Gücü: Orta Asya Ülkeleri ile Karşılaştırmalı Analizi. Türk Tarım ve Doğa Bilimleri Dergisi, 4(4): 393-401.

BESD-BİR 2018. Beyaz Et Sanayicileri ve Damızlıkçıları Birliği Derneği "İstatistikler" http://www.besd-bir.org/assets/documents/tyrkiye_ kiAi_baA_kanatl_eti_tuketimi1_1.pdf （Erişim tarihi: 30.11.2018).

Bojnec S, Ferto I 2014. Export Competitiveness of Dairy Products on Global Markets: The Case of the European Union Countries. Journal Dairy Science, 97(10): 6151-6163.

Bojnec S, Fertö I 2007. Comparative advantages in agro-food trade of Hungary, Croatia and Slovenia with the European Union. IAMO Discussion Paper No. 106, Germany.

Coxhead I 2007. A New Resource Curse? Impacts of China's Boom on Comparative Advantage and Resource Dependence in Southeast Asia. World Development, 35(7): 1099-1119.

Çoban O, Peker AE, Kubar Y 2010. Türk Tarımının Avrupa Birliği Ülkeleri Karşısındaki Sektörel Rekabet Gücü. SÜ İ̇BF Sosyal ve Ekonomik Araştırmalar Dergisi, 14(10): 247-266.

Çakmak ÖA 2005. Açılklanmış karşılaştırmalı üstünlükler ve rekabet gücü: Türkiye tekstil ve hazır giyim endüstrisi üzerine bir uygulama. Ege Akademik Review, 5(1): 65-76.

Donma MM, Donma O 2017. Beneficial Effects of Poultry Meat Consumption on Cardiovascular Health and the Prevention of Childhood Obesity. Med One, 2:e170018 DOI: 10.20900/mo.20170018

Dukic S, Tomas-Simin M, Glavas-Trbic D 2017. The Competitiveness of Serbian Agro-Food Sector. Economic of Agriculture, 64(2): 723-737.

Erkan B 2009. Ülkelerin İhracat Performanslarının Belirlenmesinde Açıklanmış Karşılaştırmalı Üstünlüklerinin Kullanılması: Yükselen Ekonomiler Örneği. Celal Bayar Üniversitesi, Sosyal Bilimler Enstitüsü, İktisat ABD, Doktora Tezi, $132 \mathrm{~s}$.

Erkan B, Arpacı BB, Yaralı F, Güvenç İ 2015. Türkiye'nin Sebze İhracatında Karşlaştırmalı Üstünlükleri. KSÜ Doğa Bilimleri Dergisi, 18(4): 70-76.

FAO 2018 Food Outlook - Biannual Report on Global Food Markets - November 2018. Rome. 104 pp. Licence: CC BY-NC-SA 3.0 IGO http://www.fao.org /3/CA2320EN/ca2320en.pdf (Erişim tarihi: 30.11.2018).

Gilbert LC 2000. The functional food trend: What's next and what Americans think about eggs. Journal 
of the American College of Nutrition, 19(5): 507512.

Güvenç İ 2019. Türkiye'de Domates Üretimi, Dış Ticareti ve Rekabet Gücü. KSÜ Tar Doğa Derg, 22(1): 57-61.

Havrila I, Gunawardana P 2003. Analyzing comparative advantage and competitiveness: An application to Australia's textile and clothing industries. Australian Economic Papers, 42(1): 103117.

Horne PLM Van 2018. Competitiveness of the EU poultry meat sector, base year 2017; International comparison of production costs. Wageningen, Wageningen Economic Research, Report.

INTRACEN 2018. International Trade Statistics. http://www.intracen.org/itc/market-info-tools/statis tics-export-product-country/ (Erişim tarihi: 30.11.2018).

Kandanuri V 2014. Comparative Advantage of India in Buffalo Meat Exports vis-à-vis Major Exporting Countries. Research Journal of Management Sciences, 3(2): 8-14.

Kanaka S, Chinadurai M 2012. A study of comparative advantage of Indian agricultural exports. Journal of Management and Science, 2(3): 1-9.

Keskin B, Demirbaş N 2012. Türkiye'de kanatlı eti sektöründe ortaya çıkan gelişmeler: Sorunlar ve öneriler. Uludağ Üniversitesi Ziraat Fakültesi Dergisi, 26(1): 117-130.

Kijboonchoo T, Kalayanakupt K 2003. Comparative Advantage and Competitive Strength of Thai Canned Tuna Export in the World Market: 19821998. ABAC Journal, 23(1): 19-33.

Lafay G 1992. The measurement of revealed comparative advantages. In Dagenais, M.G. and Muet, P.A. (Eds), International Trade Modeling. Chapman \& Hill, London, UK.

Leek S, Maddock S, Foxall G 2000. Situational determinants of fish consumption. British Food Journal, 102(1): 18-39.

Liesner HH 1958. The European Common Market and British Industry. Economic Journal, 68, 302-316.

OECD 2017. Agriculture Statistics: OECD-FAO Agricultural Outlook (Edition 2017). https://data. oecd.org/agroutput/meat-consumption. htm (Erişim tarihi: 27.11.2018).

OECD/FAO 2017. OECD-FAO Agricultural Outlook 2017-2026, OECD Publishing, Paris. http://dx.doi.org/10.1787/agr_outlook-2017-en (Erişim tarihi: 30.11 .2018 ).

OECD/FAO 2018. OECD-FAO Agricultural Outlook 2018-2027, OECD Publishing, Paris/Food and Agriculture Organization of the United Nations, Rome. https://doi.org/10.1787/agr_outlook-2018-en (Erişim 27.11.2018)
Pilinkiene V 2014. Evaluation of international competitiveness using the revealed comparative advantage indices: The case of the Baltic States, Mediterranean Journal of Social Sciences, 5(13): 353-359.

Saraçoğlu S 2015. Türkiye Tarım Ürünlerinin Avrupa Birliği Ülkelerinin Tarım Ürünleri Karşısındaki Uluslararası Rekabet Gücü. EY International Congress on Economics II, Europe and Global Economic Rebalancing, November 5-6, Ankara.

Sahinli MA, Abdul-Kareem MM 2018. Competitive Analysis: Chicken Meat Sector in Brazil and Turkey. Food Science and Nutrition Technology, 3(3): https://medwinpublishers.com/FSNT/FSNT 16000153.pdf (Erişim 26.05.2019)

Saran S, Kumar S, Gangwar LS 2013. India's exports performance in poultry products and the potential exports destinations. Agric. Econ. - Czech, 59: 134142.

Şahinli MA 2012. Rekabet Gücü: Türkiye ve Avrupa Birliği Üyesi Ülkelerde Canlı Hayvancıllk Sektörünün Durumu. Yüzüncü Yll Üniversitesi Tarım Bilimleri Dergisi, 22(2): 91-98

Terin M, Yavuz F 2018. Türkiye Peynir Sektörünün Uluslararası Rekabetçiliğinin Avrupa Birliği Ülkeleriyle Karşılaştırılmalı Analizi. Türk Tarım Gida Bilim ve Teknoloji Dergisi, 6(9): 1243-1250.

Terin M, Yıldırım İ, Aksoy A, Sarı MM 2018. Competition power of Turkey's honey export and comparison with Balkan Countries. Bulg. J. Agric. Sci., 24(1): 17-22.

Terin M. Yıldırım İ. Çiftçi K 2010. Chicken meat production and poultry meat consumption in Turkey and its progress. In Proceedings of the $2^{\text {nd }}$ Mediterrean Summit of WPSA, Antalya, Turkey.

Torok A, Jambor A 2016. Determinants of the revealed comparative advantages: The case of the European ham trade. Agric. Econ.-Czech, 62 (10): 471-481.

Ullah MS, Kazuo I 2013. Dynamics of comparative advantage and export potentials in Bangladesh. The Ritsumeikan Economic Review, 61(4): 471-48.

Utkulu U, İmer H 2009. Türk tekstil ve konfeksiyon sektörünün Avrupa Birliği tekstil ve konfeksiyon sektörü karşısındaki rekabet gücünün alt sektörler düzeyinde ölçülmesi, Rekabet Dergisi, 36, 3-43.

Vlachos I 2001. Comparative advantage and uncertainty in the international trade of Mediterranean Agricultural products: An empirical analysis. A Mediterranean Journal of Economics, Agriculture and Environment, 12(4): 42-49.

Widodo T 2008. Dynamic changes in comparative advantage: Japan "flying geese" model and its implications for China. Journal of Chinese Economic and Foreign Trade Studies, 1(3): 200-213. 